\title{
FINISHING INTERMETALLIC COATINGS IN ORDER TO REDUCE THE SURFACE ROUGHNESS
}

\author{
Tomasz Cyryl Dyl \\ Gdynia Maritime University, Faculty of Marine Engineering \\ Department of Marine Materials and Technology \\ Morska Street 81-87, 81-225 Gdynia, Poland \\ e-mail:dylu@am.gdynia.pl
}

\begin{abstract}
The paper presents a shape and grade of inserts depending on the surface roughness of the intermetallic coatings $\mathrm{NiAl}$ and $\mathrm{Ni}_{3} \mathrm{Al}$. Intermetallic coatings on nickel based were sprayed with a torch Casto-Dyn 8000 on the steel samples. Thermal spraying intermetallic coatings have been high surface roughness, and therefore they must to be finishing. Experimental research was conducted for unalloyed steel samples with thermal spraying $\mathrm{NiAl}_{\mathrm{A}}$ and $\mathrm{Ni} \mathrm{i}_{3} \mathrm{Al}$ intermetallic coatings. Before applying coatings, the samples surface was properly prepared by stream abrasive working, degreasing and finally by cleaning of oxidation products. To testing cutting inserts shape selects square and trigon made tungsten carbide and cubic boron nitride (borazon). Machining intermetallic nickel based coatings were carried out for the cutting speed $v_{c}=214 \mathrm{~m} / \mathrm{min}$ in the case of after-machining with inserts of borazon, $v_{c}=107 \mathrm{~m} / \mathrm{min}$ cutting inserts for tungsten carbide, used feed $f_{n}=0.06 \mathrm{~mm} / \mathrm{rev}$ and depth of cut $a_{p}=0.3 \mathrm{~mm}$. Intermetallic coatings are characterized by high resistance to tribology wear. These materials are used in such fields of technology, such as: electronics, energy, defense, automotive, aviation, shipbuilding, and more industry. The NiAl and $\mathrm{Ni}_{3} \mathrm{Al}$ intermetallic have found widespread applications as high - temperature structural material due to their high melting point, low density, good thermal conductivity and excellent oxidation resistance. The paper proposes the finishing flame sprayed intermetallic coatings.
\end{abstract}

Keywords: thermal spraying, intermetallic coatings, surface finishing, cutting inserts

\section{Introduction}

Intermetallic coatings can be achieved by thermal flame spraying. Thermal spraying technology is widely used due to the possibility of increasing the service properties in surface layers (strength property, tribology, anti-corrosive and decorative property) as well as layers for machine parts forging moulds busters, piston rods, gear wheels teeth, crank journals, valve seats, and combustion engine cylinders on turbine components, as restorative, as bond coats in internal combustion engine cylinders, for corrosion protection of boiler tubes and in numerous other applications requiring wear, high temperature and corrosion resistant surfaces [1, 7, 8]. Intermetallic $\mathrm{NiAl}$ and $\mathrm{Ni}_{3} \mathrm{Al}$ coatings are characterized by high fatigue resistance, heat resistance and considerable corrosion resistance and good cavitation resistance [2-4, 9, 10]. Intermetallic phases of $\mathrm{NiAl}$ and $\mathrm{Ni}_{3} \mathrm{Al}$ were used extensively as high temperature structural materials due to their low density, high melting point, good thermal conductivity and excellent oxidation resistance. In addition, the pseudo elasticity associated with the formation of stress induced martensitic in $\mathrm{NiAl}$ and high work hardening ability of $\mathrm{Ni}_{3} \mathrm{Al}$ resulted in their use in cavitation erosion environment. The intermetallic $\mathrm{NiAl}$ and $\mathrm{Ni}_{3} \mathrm{Al}$ coatings have potential applications in hydraulic machines, high - pressure pipes, hydro and low pressure steam turbine blades, ship propellers, pumps and valves diesel engines [2,3].

Coatings obtained by thermal spraying have high surface roughness. Therefore, these coatings must be subjected to after-machining. The most commonly used the finishing: turning and grinding. Thermal flame sprayed coatings are applied taking into account the allowance for the finishing. Finishing should ensure not only the thickness of coatings related to the nominal 
dimension of the object, but also to obtain the required surface roughness. Choosing parameters (feed rate, depth of cut, cutting speed) machining coatings must be remembered that the tool does not always cut sprayed particles, but may cause them breaking the surface. In papers [5, 6] was presented the influence of the shape and grade inserts on the geometric structure after - machining alloy and composite coatings. Based on the results $[5,6]$ it can be concluded that the smallest roughness of the coatings obtained with trigon inserts with grade CB7015 and trigon inserts with grade GC3215. This paper approach finishing intermetallic coatings with specified tools: WNMG 080408 S01030A CB7015, WNMG 080408 - KF GC3215. Because of the low surface roughness obtained satisfactory composite coatings have been treated with a square insert SNGA 120408 S01030A CB7015, it also applied to the cutting machining of intermetallic coatings.

\section{Methodology of Research}

Technological quality of coatings produced by thermal spraying depends on many factors such as the type of gas, the flow rate and pressure used in the process. It is now clear that the particle velocity is an important process variable that affects the melting of the particles and ultimately the density and adhesion of the deposited material. Therefore used to experiment Casto - Dyn 8000 torch $[11,12]$.

Flame spraying intermetallic coatings were carried out assuming the following process technology parameters:

- oxygen pressure: $0.4 \mathrm{MPa}$,

- air pressure: $0.3 \mathrm{MPa}$,

- acetylene pressure: $0.07 \mathrm{MPa}$,

- speed of the torch: $20 \mathrm{~m} / \mathrm{min}$,

- feed rate: $3 \mathrm{~mm} / \mathrm{rev}$,

- distance from the torch surface to be sprayed: $100 \mathrm{~mm}$,

- number of applied layers: 6.

Steel substrate pre-heated in the temperature range $60-100^{\circ} \mathrm{C}$. Flame spraying was carried out at temperatures exceeding $150^{\circ} \mathrm{C}$.

Surface roughness after thermal spraying intermetallic coatings are obtained high value. After thermal spraying (before machining) the arithmetical mean deviation coatings surface roughness profile was $\mathrm{Ra}=6.1 \mu \mathrm{m}$ for intermetallic $\mathrm{Ni} 3 \mathrm{Al}$ coatings and $\mathrm{Ra}=5.1 \mu \mathrm{m}$ for intermetallic NiAl coatings. They require a finishing surface coatings.

To determine the parameters of machining coatings based on nickel flame sprayed onto the substrate steel, preliminary study was conducted longitudinal turning high precision. Fought with different cutting speed $\left(v_{c}=45-214 \mathrm{~m} / \mathrm{min}\right)$, feed rate $\left(f_{n}=0.06-0.2 \mathrm{~mm} / \mathrm{rev}\right)$ and depth of cut $\left(a_{p}=\right.$ 0.05-0.3 mm).

Based on analysis of test results determined that the best surface quality obtain samples of intermetallic coatings for technology parameters:

- cutting speed: $v_{c}=214 \mathrm{~m} / \mathrm{min}$ for inserts of borazon,

- cutting speed: $v_{c}=107 \mathrm{~m} / \mathrm{min}$ for inserts of tungsten carbide,

- feed: $f_{n}=0.06 \mathrm{~mm} / \mathrm{rev}$,

- depth of cut: $a_{p}=0.3 \mathrm{~mm}$.

The research program and shape and grade cutting inserts using to turning intermetallic coatings is presented in Tab. 1.

After - machining, were subjected to a thorough external cylindrical surfaces of steel samples of coatings $\phi 41 \mathrm{~mm}$ in diameter with a thickness of $2 \mathrm{~mm}$. To determine the optimal geometry of the cutting tool, now it is synonymous with the selection of the optimum shape and dimensions of the insert and the appropriate holder, square and trigon made of tungsten carbide (with grades: GC3215) and cubic boron nitride (CBN, grade CB7015) were chosen. 
Tab. 1. The shape and grade cutting inserts using to turning intermetallic NiAl and $\mathrm{Ni}_{3} \mathrm{Al}$ coatings

\begin{tabular}{|cccc|}
\hline $\begin{array}{c}\text { Insert } \\
\text { Shape }\end{array}$ & $\begin{array}{c}\text { Insert } \\
\text { Type }\end{array}$ & $\begin{array}{c}\text { Holder } \\
\text { Type }\end{array}$ & $\begin{array}{c}\text { Insert } \\
\text { Grade }\end{array}$ \\
\hline Square & SNGA 120408 S01030A & DSDNN 2525M 12 & CB7015 \\
\hline Trigon & WNMG 080408 S01030A & DWLNRL 2525M 08 & \multirow{2}{*}{ CB7015 } \\
\hline \hline Trigon & WNMG 080408 - KF & DWLNRL 2525M 08 & \multirow{2}{*}{ GC3215 } \\
\hline
\end{tabular}

The microhardness of intermetallic coatings $\mathrm{NiAl}$ and $\mathrm{Ni3} A \mathrm{Al}$ measurement was carried out by means of the hardness tester FM-800, which allowed precise and semiautomatic methods of measurement by Vickers (HV). The microhardness measurements were made according to PN-EN ISO 6507-1:1999, the pressure force of $20 \mathrm{~N}$, the load time was 10 seconds. Microhardness of $\mathrm{NiAl}$ coatings get value $242 \mathrm{HV}$ and $\mathrm{Ni}_{3} \mathrm{Al}$ coatings be equal to $213 \mathrm{HV}$ after thermal spraying.

Surface roughness after thermal spraying and machining was measured with a HOMMEL TESTER T1000 profile meter in the Department of Marine Materials and Technology at Gdynia Maritime University. The length of test sample was $4.8 \mathrm{~mm}$, and the sampling length was $0.8 \mathrm{~mm}$. On the basis of the arithmetical mean deviation of roughness profile (parameter Ra) - the surface roughness reduction ratio of intermetallic coatings was determined.

\section{Results of Experimental Research}

The study allowed for determination, that there are relationships between the surface texture of intermetallic coatings and the type of grade used and the shape of the inserts. Trigon inserts WNMG 080408 - KF of GC3215 and WNMG 080408 S01030A of CB7015 were characterized by a smaller flank wear as compared to a square insert with SNGA 120408 S01030A CB7015.

Figure 1 shown the arithmetical mean deviation of the assessed profile for turned intermetallic coatings. After turning coatings using square insert SNGA120408S01030A 7015, specifies that the arithmetical mean deviation of the assessed profile reached a greatest value of $\mathrm{Ra}=1.18 \mu \mathrm{m}$ for $\mathrm{Ni}_{3} \mathrm{Al}$ coatings and $\mathrm{Ra}=1.22 \mu \mathrm{m}$ for $\mathrm{NiAl}$ coatings. In comparison to the roughness of the surface texture with the trigon insert made of the same grades (CB7015) and also with the trigon of tungsten carbide (about the grades: GC3215). The lowest surface roughness (Fig. 1) is achieved, coating turned the trigon insert made of tungsten carbide determined that the minimum surface roughness of intermetallic $\mathrm{Ni}_{3} \mathrm{Al}$ coatings are obtained for grade $\mathrm{GC} 3215(\mathrm{Ra}=0.55 \mu \mathrm{m})$.

Reduced depth of roughness profile valley is described by (Rvk) parameter (which should be the highest). Parameter (Rk) defines the core roughness depth (which should be the lowest). Parameter (Rpk) variable of the reduced peak height (which should be the lowest) is characteristic for the upper surface layer that quickly undergoes abrasion after the commencement of, for example, engine running. It is a measure of the working surfaces ability to keep the lubricant in the valleys created mechanically (Fig. 2).

After - machining the external cylindrical steel samples of coated determined that there are relationships between surface texture and the type of material used and the shape of the cutting inserts. After analysing the results of cutting determined that due to obtaining the smallest surface roughness intermetallic coatings, it was expedient to use trigon inserts made of tungsten carbide with grade GC3215 and trigon inserts made of cubic boron nitride with grade CB7015.

Coating after machining had much lower surface roughness compared to the surface of the thermal spraying. After machining of intermetallic coatings $\mathrm{NiAl}$ and $\mathrm{Ni} 3 \mathrm{Al}$ was determined that the arithmetical mean deviation (Fig. 1) and the material ratio curve surface roughness parameters (Fig. 2) take the smallest value for trigon inserts of grade GC3215. 


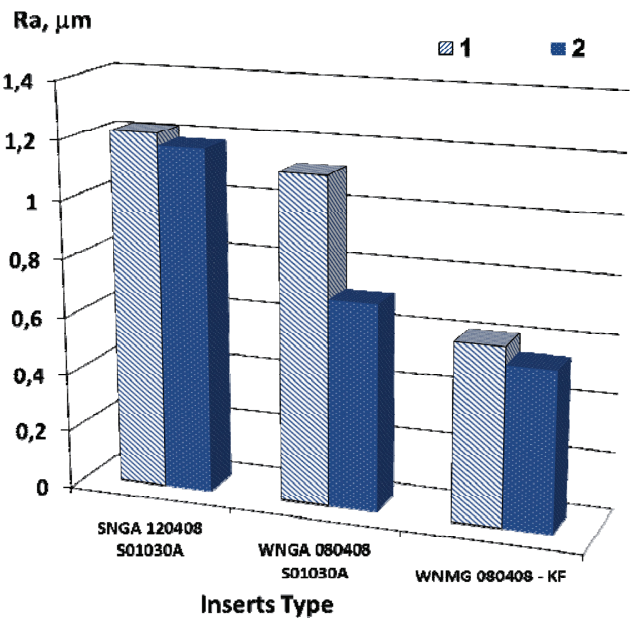

Fig. 1. The arithmetical mean deviation for intermaetallic coatings: 1 - coatings $\mathrm{NiAl}$ and 2 - coatings $\mathrm{Ni}_{3} \mathrm{Al}$
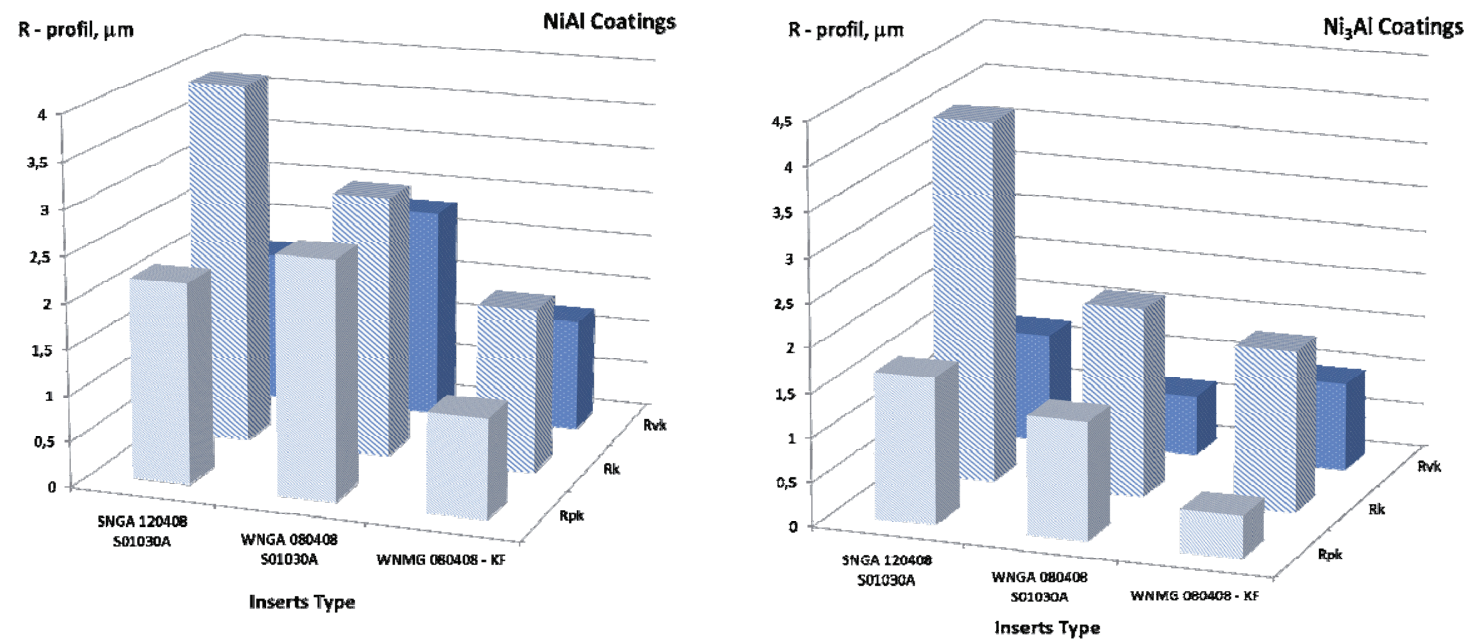

Fig. 2. The characterised parameters of the material ratio curve for intermetallic NiAl (left) and Ni3Al (right) coatings after-machining for selected inserts type

Figure 3 and Fig. 4 shows the material ratio curve surface roughness intermetallic coatings $\mathrm{NiAl}$ and $\mathrm{Ni}_{3} \mathrm{Al}$ for different type inserts. On the basis of analysis of experimental results after turning intermetallic coatings for inserts cutting by the trigon of the grade GC3215 can be determined that the roughness profile parameters and parameter values of the material ratio curve reached the lowest values.

a)

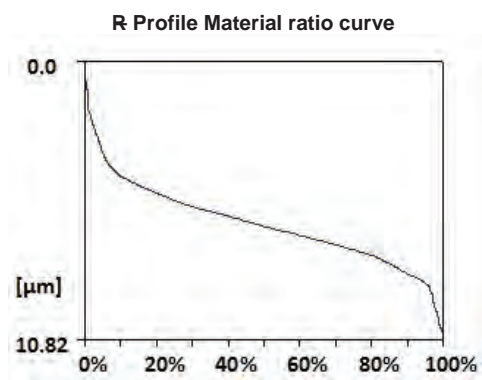

b)

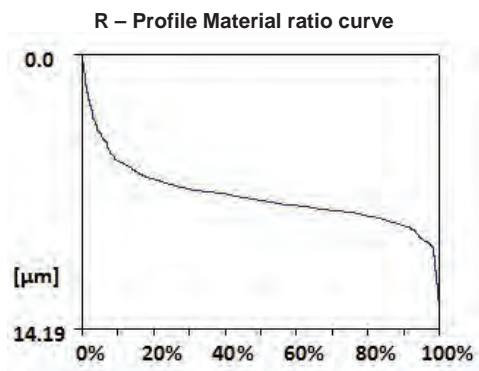

c)

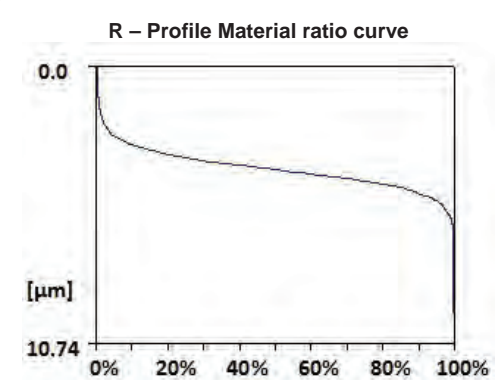

Fig. 3. The material ratio curve surface roughness intermetallic coatings NiAl for cutting inserts: a) square SNGA 120408 S01030A CB7015 $(R a=1.22 \mu \mathrm{m})$ and b) trigon WNMG 080408 S01030A CB7015 $(R a=1.12 \mu \mathrm{m})$ and c) trigon WNMG 080408 - KF GC3215 $(R a=0.61 \mu m)$ 
a)

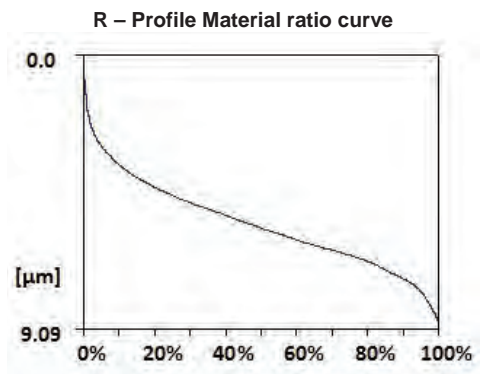

b)

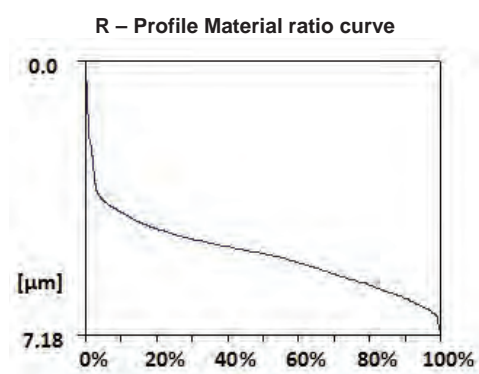

c)

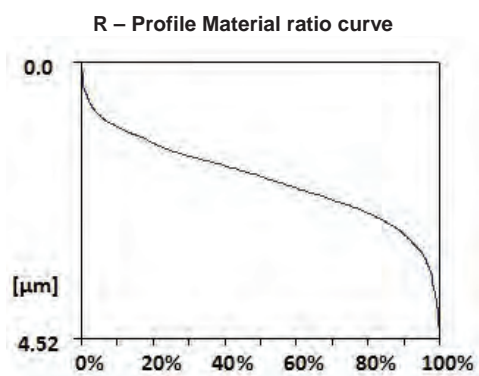

Fig. 4. The material ratio curve surface roughness intermetallic coatings $N i_{3} A l$ for cutting inserts: a) square SNGA 120408 S01030A CB7015 $(R a=1.18 \mu \mathrm{m})$ and b) trigon WNMG 080408 S01030A CB7015 $(R a=0.71 \mu \mathrm{m})$ and c) trigon WNMG 080408 - KF with GC3215 (Ra = $0.55 \mu \mathrm{m})$

Figure 5 and Figure 6 shows the values of the asymmetry factor roughness (skewness) intermetallic coatings $\mathrm{NiAl}$ and $\mathrm{Ni}_{3} \mathrm{Al}$ for different type inserts.

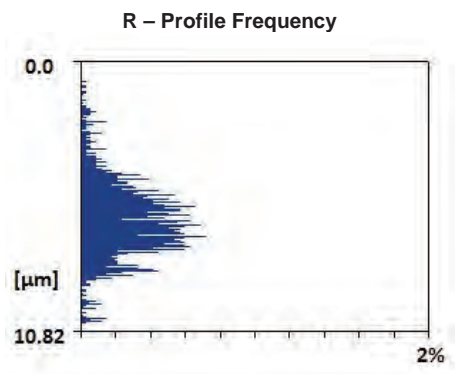

b)

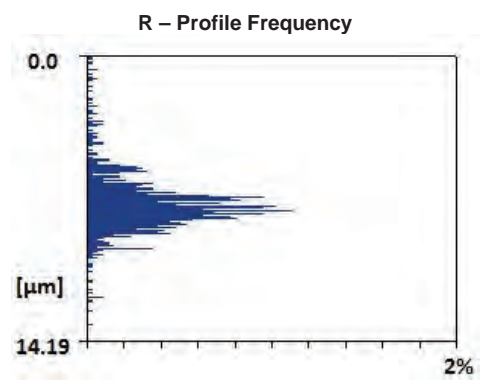

c)

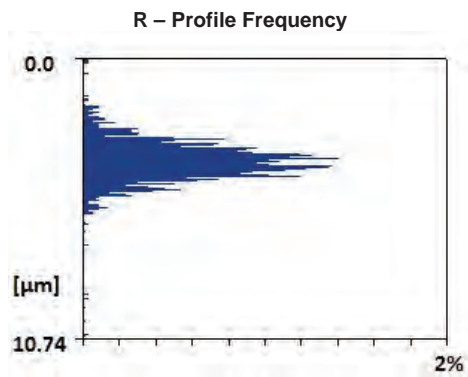

Fig. 5. The skewness for intermetallic coatings NiAl for cutting inserts: a) square SNGA 120408 S01030A CB7015 $($ Rsk $=0.415 \mu \mathrm{m})$ and b) trigon WNMG 080408 S01030A CB7015 (Rsk = $1.044 \mu \mathrm{m})$ and c) trigon WNMG 080408 - KF GC3215 (Rsk = - $0.537 \mu m)$

a)

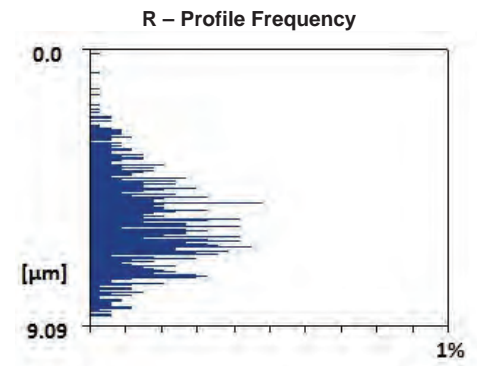

b)

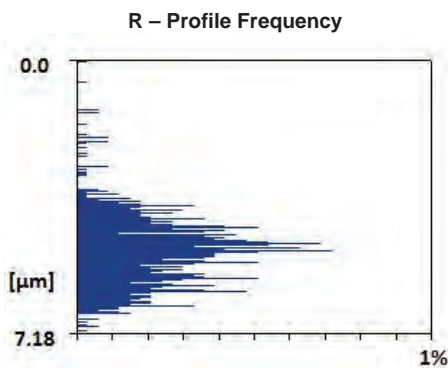

c)

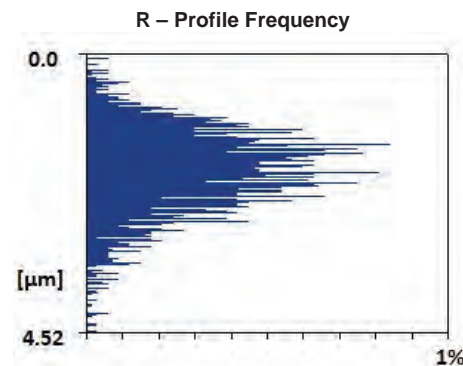

Fig. 6. The skewness for intermetallic coatings Ni3Al for cutting inserts: a) square SNGA 120408 SO1030A CB7015 $(R s k=0.407 \mu \mathrm{m})$ and b) trigon WNMG 080408 S01030A CB7015 (Rsk=0.909 $\mu \mathrm{m})$ and c) trigon WNMG 080408 - KF with GC3215 (Rsk = - $0.423 \mu \mathrm{m})$

The values of the asymmetry factor (Rsk - skewness) roughness profile are negative for turning intermetallic coatings for trigon inserts of grade GC3215. Therefore, the machining of the surface to achieve a surface characterized by low values of the parameters of the reduced peak height (Rpk) and a core roughness depth (Rk).

\section{Summary and Conclusions}

Profile skewness indicates the distribution of symmetry with respect to the elevation profile of the average. Skewness is zero for a symmetric profile. Skewness of negative value indicates the concentration of the material in the profile near the vertices, which is plateau shaped surface. 
Skewness values are greatly influenced by the individual extreme profile peaks and valleys.

It shows, however, that most of the amplitude distribution function is above the average. Then, the test surface can be considered as a good bearing surface.

Experimental studies on effect of a shape and grade of inserts depending on the surface roughness of the intermetallic coatings $\mathrm{NiAl}$ and $\mathrm{Ni} 3 \mathrm{Al}$, showed that there was a decrease in surface roughness after turning as compared to the surface of the thermal spraying.

After finishing intermetallic $\mathrm{NiAl}$ and $\mathrm{Ni3} \mathrm{Al}$ coatings, it can be concluded that:

- is selected the best tool for turning coatings to achieve a good surface quality,

- surface texture is very important where it has a direct influence on the quality of the elements machine parts,

- using trigon inserts of grade CB7015 and grade GC3215 you can get a satisfactory surface roughness, determined that the roughness profile parameters and parameter values of the material ratio curve reached the lowest values,

- using trigon inserts made of tungsten carbide (with grades: GC3215) the skewness a negative value is achieved, it shows, however, that most of the amplitude distribution function is above the average profile, the test surface can be considered a good bearing surface,

- would need to be used trigon inserts with grade GC3215, due to the surface quality coatings and durability of the inserts for turning intermetallic coatings,

- it can be using for regeneration and production of the intermetallic $\mathrm{NiAl}$ and $\mathrm{Ni} 3 \mathrm{Al}$ coatings of the machine parts and finishing by trigon inserts of tungsten carbide WNMG 080408 - KF GC3215.

\section{References}

[1] Barbezat, G., Thermal spray coatings for tribological applications in the automotive industry, Advanced Engineering Materials, Vol. 8, pp. 678-681, 2006.

[2] Chang, J. T., Yeh, C. H., He, J. L., Chen, K. C., Cavitation erosion and corrosion behavior of Ni - Al intermetallic coatings, Wear, 255, pp. 162-169, 2003.

[3] Duraiselvam, M., Galun, R., Wesling, V., Mordike, B. L., Reiter, R., Oligmüller, J., Cavitation erosion resistance of AISI 420 martensitic stainless steel laser-clad with nickel aluminide intermetallic composites and matrix composites with TiC reinforcement, Surface and Coatings Technology, Vol. 201, pp. 1289-1295, 2006.

[4] Dyl, T., Starosta, R., Skoblik, R., Effect of the unit pressure on the selection parameters of intermetallic coatings NiAl and Ni3Al after plastic working, Solid State Phenomena, Vol. 165, pp. 19-24, 2010.

[5] Dyl, T., Starosta, R., Determining the effect of the geometry and type of inserts on the geometric structure of turned composite coatings, Inżynieria Materiałowa, No. 6, pp. 701-704, 2012.

[6] Dyl, T., Starosta, R., The influence of the shape and grade inserts on the geometric structure turned alloy coatings, Inżynieria Materiałowa, No. 4, pp. 395-398, 2011.

[7] Ernst, P., Barbezat, G., Thermal spray applications in powertrain contribute to the saving of energy and material resources, Surface and Coatings Technology, Vol. 202, pp. 4428-4431, 2008.

[8] Sampath, S., Jiang, X.Y., Matejicek, J., Prchlik, L., Kulkarni, A., Vaidya, A., Role of thermal spray processing method on the microstructure, residual stress and properties of coatings: an integrated study for Ni-5 wt.\%Al bond coats, Materials Science and Engineering, Vol. 364, pp. 216-231, 2004.

[9] Starosta, R., Szczepaniak, P., The corrosion resistance estimation of NiAl and NizAl plasma sprayed coatings, Inżynieria Materiałowa, No 3, pp. 540-543, 2006.

[10] Starosta, R., Skoblik, R., Dyl, T., The influence of plastic working on the selection properties of the nickel-aluminium alloy coatings, Journal of Kones, Vol. 14, No. 2, pp. 441-448, 2007.

[11] Starosta R., Texture of surface of coatings obtained using the "Casto-Dyn 8000" torch, after burnishing treatment, Journal of KONES, Vol. 18, No.3, pp. 413-420, 2011.

[12] Starosta R., The influence of torch type on properties of $\mathrm{Ni}-\mathrm{Al}$ and $\mathrm{Ni}$-Al-Al $\mathrm{A}_{2} \mathrm{O}_{3}$ coatings obtained by flame spraying, Inżynieria Materiałowa, Vol. 182, No. 4, pp. 743-746, 2011. 